[Chem. Pharm. Bull. $]$

32( 3$) 1011-1017(1984)$

\title{
Determination of Some Basic Samples in Anhydrous Acetic Acid by Complementary Tristimulus Colorimetry
}

\author{
Shigeru Yoshida, ${ }^{*}$ Kayoko Oda and Shingo Hirose \\ Kyoto College of Pharmacy, Nakauchi-cho 5, Misasagi, \\ Yamashina-ku, Kyoto 607, Japan
}

(Received June 2, 1983)

\begin{abstract}
In non-aqueous titration, the color shade at the equivalence point was decided graphically by utilizing complementary tristimulus colorimetry. It was also shown that the color shade at the equivalence point could be decided from the $\mathrm{p} K_{\mathrm{a}}$ value in aqueous solution of a weakly basic sample. Visual detection of the end-point in anhydrous acetic acid was possible when the sample concentration was higher than $10^{-2} \mathrm{M}$.

A general expression for determination of the equivalence point is presented, and factors influencing the titration are discussed.
\end{abstract}

Keywords — non-aqueous titration; indicator transition; visual end-point indication; complementary tristimulus colorimetry; stoichiometric relationship; theoretical titration curve

The visual end-point indication in non-aqueous titration is influenced by many factors, such as apparent formation constant, sample concentration and color shade of the indicator at the equivalence point. The theory of non-aqueous titration has been considered by several authors. ${ }^{1,2)}$ Tanaka et al. ${ }^{3)}$ gave a general theoretical treatment of acid-base titration in glacial acetic acid. However, these theories have not been practically applied.

In our previous paper, ${ }^{4)}$ a quantitative equation for titration was derived from the relationship between the chemical stoichiometric factors and the indicator transition. The theoretical and experimental results agreed well near the equivalence point of the titration. The equation could be used to determine weakly basic samples at comparatively low concentrations $\left(10^{-3}-10^{-4} \mathrm{M}\right.$ order $)$.

In the present work, the color shade at the equivalence point was graphically decided in visual titration by utilizing the chemical stoichiometric relationships and applied to the practical titration of a high sample concentration. No attempt is made to discuss in detail indicator color at the equivalence point in non-aqueous titration, however.

At low sample concentration, the indicator was not appreciably discolored at the equivalence point. From the practical point of view, visual detection of the end-point in anhydrous acetic acid was possible when the sample concentration was higher than $10^{-2} \mathrm{M}$. It was found by visual titration that the $\mathrm{p} K_{\mathrm{a}}$ value in aqueous solution of a weakly basic sample is related to the color shade at the equivalence point.

The color shades near the equivalence point were represented quantitatively by the complementary color point, which is an important parameter in the complementary tristimulus colorimetry (CTS) method. ${ }^{5,6)}$ The application of the CTS method to multicolorant systems offers distinct advantages not only for the description of color but also for the practical analysis of colored solutions. This approach was found to be applicable to the study and evaluation of chemical species in the titration process. A general expression for the determination was obtained and various factors influencing the titration were considered for the determination of weakly basic samples in anhydrous acetic acid with methylrosaniline chloride (crystal violet, c.v.) as an indicator and perchloric acid as a titrant. 


\section{Experimental}

Apparatus_-Photometric determination was carried out with a Shimadzu MPS-50L spectrophotometer. Titrant was added with a Metrohm piston buret (capacity, $5 \mathrm{ml}$ ).

Materials__ Anhydrous Acetic Acid: Glacial acetic acid was freed from water by repeated distillation.

Perchloric Acid Solution in Anhydrous Acetic Acid, $0.1 \mathrm{~m}$ : Dissolve $8.5 \mathrm{ml}$ of perchloric acid (70-72\%) in anhydrous acetic acid, add $22.2 \mathrm{ml}$ of acetic anhydride and make the volume up to $1000 \mathrm{ml}$ with anhydrous acetic acid. Standardize against potassium hydrogen phthalate and dilute as required.

Crystal Violet, $10^{-3} \mathrm{M}$ : Recrystallize twice from acetone-ethyl acetate (2:1), weigh accurately about $44.4 \mathrm{mg}$ of crystal violet (previously dried at $100^{\circ} \mathrm{C}$ for $2 \mathrm{~h}$ ) and dissolve in $100 \mathrm{ml}$ of anhydrous acetic acid in a volumetric flask.

All other weakly basic samples were of pharmacopoeia or analytical grade and were prepared as solutions of $10^{-1}-10^{-3} \mathrm{M}$.

CTS Method - The CTS method can be applied to the analysis of a mixture of free and complex forms of an indicator. In the CTS method, three ranges are selected in the absorption spectra, each range containing an appropriate number $(5-10)$ of wavelengths at which absorbance readings are taken. The sums of the absorbance readings in the three ranges (denoted by $R u, R v$ and $R w$ ) are used to calculate the complementary color point $Q u, Q v$ and $Q w$, defined by the following Eqs. (1) and (2).

$$
\begin{aligned}
& R r=\sum_{i=1}^{n} A r i \\
& Q r=\frac{R r}{\sum_{r}^{u, v, w} R r}=\frac{R r}{J}
\end{aligned}
$$

Ari and $R r$ are the absorbance readings and the sum of the absorbance readings in the $r$ range. The subscript $r$ is the generic notation for $u, v$ and $w . Q r$ is independent of the concentration of a colorant and has a value which is characteristic of the particular colorant. The overall absorptivity, $E$ is related to the analytical concentration by Eq. (3),

$$
J=E \cdot C \cdot l
$$

where $C$ is the analytical concentration of the indicator and $l$ is the length of light pass.

When a colorant is present in the solution, it is represented by a discrete point in the $Q r$ plot, that is a rectangular plot of $Q u$ and $Q v$ (when it is more convenient, the pairs $Q u-Q w$ or $Q v-Q w$ can be plotted). A second colorant will be represented by another point in the $Q r$ plot. If the colorants are $\mathrm{I}$ and $\mathrm{IH}^{+} \mathrm{X}^{-}$, any mixture of these two colorants $(Q r m)$ is represented by a point on a straight line which connects two fixed points, $Q r_{1}$ and $Q r_{\text {IHX }}$ (Fig. 1).

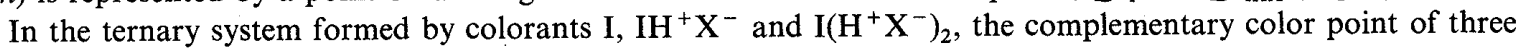
colorants is represented by three fixed points (Fig. 1). Any complementary color point of a three-colorant mixture will be located within the triangular shape formed by connecting the three fixed points with straight lines.

In Fig. 1, if $\mathrm{M}_{2}$ is the color point of the mixture, a straight line drawn from $\mathrm{I}\left(\mathrm{H}^{+} \mathrm{X}^{-}\right)_{2}$ through $\mathrm{M}_{2}$ will intersect the line at a certain point $\left(\mathrm{m}_{1}\right)$ between $\mathrm{I}$ and $\mathrm{IH}^{+} \mathrm{X}^{-}$. The point $\mathrm{m}_{1}$ gives the indicator transition in terms of $\mathrm{I}$ and $\mathrm{IH}^{+} \mathrm{X}^{-}$. Similarly a straight line from $\mathrm{I}$ through $\mathrm{M}_{2}$ will intersect the line at a certain point $\left(\mathrm{m}_{2}\right)$ between $\mathrm{IH}^{+} \mathrm{X}^{-}$ and $\mathrm{I}\left(\mathrm{H}^{+} \mathrm{X}^{-}\right)_{2}$. The point $\mathrm{m}_{2}$ gives the indicator transition in terms of $\mathrm{IH}^{+} \mathrm{X}^{-}$and $\mathrm{I}_{(}\left(\mathrm{H}^{+} \mathrm{X}^{-}\right)_{2}$.

Indicator Transition of Crystal Violet_-Absorption spectra of solutions containing various molar ratios of

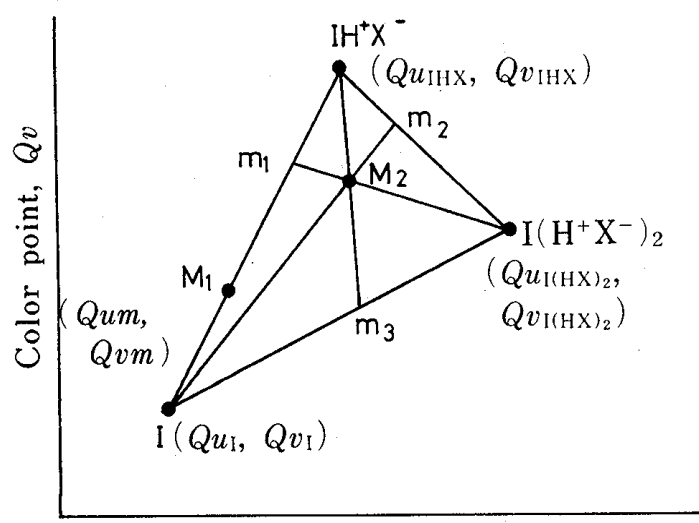

Color point, $Q u$
Fig. 1. $Q u-Q v$. Plot for Two- and ThreeColorant Systems

$\mathrm{I}, \mathrm{IH}^{+} \mathrm{X}^{-}$and $\mathrm{I}\left(\mathrm{H}^{+} \mathrm{X}^{-}\right)_{2}$ : Complementary color points of pure colorants; $\mathrm{I}, \mathrm{IH}^{+} \mathrm{X}^{-}$and $\mathrm{I}\left(\mathrm{H}^{+} \mathrm{X}^{-}\right)_{2}$, respectively.

$\mathrm{M}_{1}$ : Complementary color point $(\mathrm{Qum}, \mathrm{Qvm})$ in a system of two colorants, I and $\mathrm{IH}^{+} \mathrm{X}^{-}$.

$\mathrm{M}_{2}$ : Complementary color point in a system of three colorants.

$\mathrm{m}_{1}, \mathrm{~m}_{2}, \mathrm{~m}_{3}$ : Complementary color point of twocolorant mixture determined by the graphical approach from a color point, $\mathbf{M}_{2}$ of the three components. 

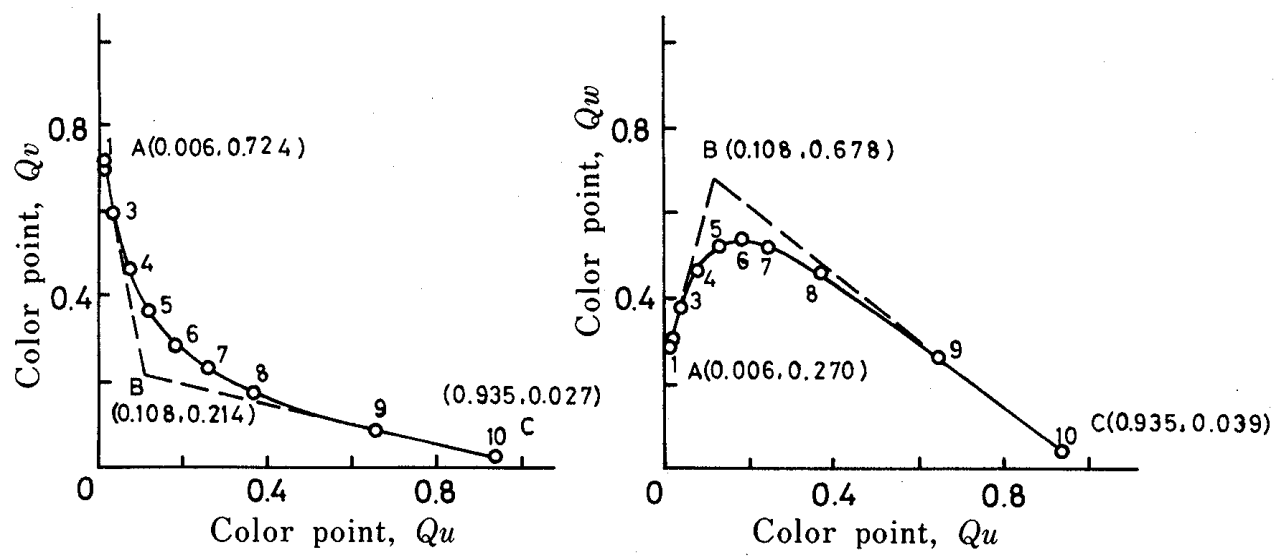

Fig. 2. $Q r$ Plot for the Crystal Violet $-\mathrm{HClO}_{4}$ System

Crystal violet: $5 \times 10^{-6} \mathrm{M}$.

Molar ratio $\left(C_{\mathrm{HX}} / C_{\mathrm{I}}\right): 1,0 ; 2,3.0 ; 3,3.5 ; 4,4.0 ; 5,5.0 ; 6,7.0 ; 7,8.0 ; 8,10.0 ; 9,18.0 ; 10,75.0$.

$u$ range, $415-460 \mathrm{~nm} ; v$ range, $550-595 \mathrm{~nm} ; w$ range, $600-645 \mathrm{~nm}$.

Points A, B and C denote chemical species and color shades of indicator as below.

A, I (violet); B, $\mathrm{IH}^{+} \mathrm{X}^{-}$(green); C, I( $\left.\mathrm{H}^{+} \mathrm{X}^{-}\right)_{2}$ (yellow).

TABLE I. CTS Parameters of Crystal Violet and C. $\mathrm{V}\left(\mathrm{H}^{+} \mathrm{ClO}_{4}{ }^{-}\right)$

\begin{tabular}{|c|c|c|c|c|c|c|c|c|}
\hline & $R u$ & $\begin{array}{l}R r \\
R v\end{array}$ & $R w$ & $J$ & $E$ & $Q u$ & $\begin{array}{l}Q r \\
Q v\end{array}$ & $Q w$ \\
\hline $\begin{array}{c}\mathrm{I} \\
\mathrm{IH}^{+} \mathrm{X}^{-}\end{array}$ & 1.09 & 135.23 & 50.53 & 186.85 & $\begin{array}{l}3737 \times 10^{4} \\
\left.2565 \times 10^{4 a}\right)\end{array}$ & $\begin{array}{l}0.006 \\
0.108\end{array}$ & $\begin{array}{l}0.724 \\
0.214\end{array}$ & $\begin{array}{l}0.270 \\
0.678^{b)}\end{array}$ \\
\hline
\end{tabular}

I, Crystal violet; $\mathrm{IH}^{+} \mathrm{X}^{-}, \mathrm{C} . \mathrm{V}\left(\mathrm{H}^{+} \mathrm{ClO}_{4}^{-}\right)$.

a) $E_{\mathrm{IHX}}$ was determined in our previous paper. ${ }^{4)}$

b) These values were obtained graphically by extrapolation in Fig. 2 .

perchloric acid and a constant concentration of crystal violet were measured in the visible region. From the absorption spectra, the complementary color points can be calculated. These $Q r$ points can be placed on a $Q u-Q v$ plot or a $Q u-Q w$ plot and are shown in Fig. 2. By extrapolation of the plot in Fig. 2, a triangular shape is obtained, and $Q r$ points should fall on the lines or inside the triangular shape. From the definition of the CTS method, chemical species corresponding to $Q r$ points (2, 3, 9 in Fig. 2) which are on the straight line are mixtures of the two pure colorants corresponding to the ends of the line. For $Q r$ points ( $4-8$ in Fig. 2) inside the triangular shape, the chemical species are mixtures of three pure colorants. The three species of the indicator correspond to complex C.V. (violet), C. $\left(\mathrm{H}^{+} \mathrm{ClO}_{4}{ }^{-}\right)$(green) and $\mathrm{C} . \mathrm{V}\left(\mathrm{H}^{+} \mathrm{ClO}_{4}{ }^{-}\right)_{2}$ (yellow) and the movement of the $Q r$ plot in the triangular shape results from the successive formation of these complexes. A slight movement of each complementary color point in response to a large variation of molar ratio $\left(C_{\mathrm{HClO}_{4}} / C_{\mathrm{C} \text {.v. }}\right)$ is due to a comparatively small formation constant between the indicator and the titrant $\left(K_{\mathrm{IHX}}=2.7 \times 10^{4}\right){ }^{4)}$ Accordingly, the color transition of crystal violet can not be decided accurately even in ordinary non-aqueous titration. ${ }^{7)}$ The main CTS parameters of crystal violet used in the present paper are listed in Table I.

Procedure of Determination-All analytical procedures were performed in an air-conditioned room at $20 \pm 1^{\circ} \mathrm{C}$. A sample solution of $1 \mathrm{ml}\left(10^{-1}-10^{-3} \mathrm{M}\right)$ was placed in a $10 \mathrm{ml}$ volumetric flask, and $0.05 \mathrm{ml}$ of $10^{-3} \mathrm{M}$ crystal violet was added with a piston buret. The mixture was titrated with $10^{-1}-10^{-3} \mathrm{M}$ perchloric acid (corresponding to the sample concentration) from the piston buret, with gentle stirring. When the initial violet color changed from blue to green, the titration was stopped at any color shade of that color and the solution was made up to the marked line with acetic acid. The absorption spectrum in the visible region was measured in a $1 \mathrm{~cm}$ quartz cell against anhydrous acetic acid as a reference, and the three ranges for the CTS method were selected ( $u, v$ and $w$ ranges). From the sum of ten absorbance readings in each range, the complementary color point was calculated by using Eqs. (1), (2) and (3).

Calculation of Stability Constant_-The conditional stability constants contained in the quantitative equation were also determined by the CTS method from the stoichiometric relationships of chemical species in the solution. ${ }^{4)}$ 


\section{Results and Discussion}

\section{Chemical Stoichiometric Relationships}

In the titration reaction between a titrant $\mathrm{HX}$ (perchloric acid) and sample B (a weak base) in the presence of an indicator I (crystal violet), the following chemical equilibria hold. In the following equilibria, it is assumed that the volume does not change during the titration and that the activity coefficient is unity in acetic acid. ${ }^{2)}$

$$
\begin{aligned}
& \mathrm{B}+\mathrm{HX} \rightleftharpoons \mathrm{BH}^{+} \mathrm{X}^{-} \\
& \mathrm{I}+\mathrm{HX} \rightleftharpoons \mathrm{IH}^{+} \mathrm{X}^{-}
\end{aligned}
$$

From these equilibria, the apparent formation constants are

$$
\begin{gathered}
K_{\mathrm{BHX}}=\frac{\left[\mathrm{BH}^{+} \mathrm{X}^{-}\right]}{[\mathrm{B}][\mathrm{HX}]} \\
K_{\mathrm{IHX}}=\frac{\left[\mathrm{IH}^{+} \mathrm{X}^{-}\right]}{[\mathrm{I}][\mathrm{HX}]}
\end{gathered}
$$

Chemical stoichiometric relationships mean that Eqs. (8)-(10) hold throughout the titration.

$$
\begin{aligned}
& C_{\mathrm{HX}}=[\mathrm{HX}]+\left[\mathrm{BH}^{+} \mathrm{X}^{-}\right]+\left[\mathrm{IH}^{+} \mathrm{X}^{-}\right] \\
& C_{\mathrm{B}}=[\mathrm{B}]+\left[\mathrm{BH}^{+} \mathrm{X}^{-}\right] \\
& C_{\mathrm{I}}=[\mathrm{I}]\left[\mathrm{IH}^{+} \mathrm{X}^{-}\right]
\end{aligned}
$$

$C_{\mathrm{HX}}, C_{\mathrm{B}}$ and $C_{\mathrm{I}}$ refer to the total concentrations of the acid $\mathrm{HX}$, the base $\mathrm{B}$ and indicator I, respectively.

\section{Application to Visual Titration}

In titration of a comparatively high concentration of sample, the end-point may be decided from the change in color of the indicator. ${ }^{8}$ However, some indicators have no simple color change but pass successively through a wide range of color shades, especially in anhydrous acetic acid. ${ }^{9)}$ The choice of a suitable indicator for a titration is still largely a matter of experience. Further, the color shade at the equivalence point is affected by the basicity of the sample and the concentration. In such cases, it is best to perform a preliminary titration of a given sample with potentiometric indication, also adding the indicator to the solution. For the sake of simplicity, it is desirable to determine preliminarily the color shade of the indicator at the equivalence point.

In visual titrations, it is assumed that the total concentration of indicator is negligibly small as compared with $C_{\mathrm{HX}}$ and $C_{\mathrm{B}}$, and the following stoichiometric relationships hold.

$$
\begin{aligned}
& C_{\mathrm{HX}}=[\mathrm{HX}]+\left[\mathrm{BH}^{+} \mathrm{X}^{-}\right] \\
& C_{\mathrm{B}}=[\mathrm{B}]+\left[\mathrm{BH}^{+} \mathrm{X}^{-}\right]
\end{aligned}
$$

From Eqs. (6), (11) and (12), the titration ratio $a$ is denoted by Eq. (13)

$$
a \equiv \frac{C_{\mathrm{HX}}}{C_{\mathrm{B}}}=\left(1+\frac{1}{K_{\mathrm{BHX}}[\mathrm{HX}]}\right)^{-1}+\frac{[\mathrm{HX}]}{C_{\mathrm{B}}}
$$

By utilizing Eq. (13), $[\mathrm{HX}]$ at the equivalence point $\left([\mathrm{HX}]_{\text {e.p. }}\right)$ is given by Eq. (14).

$$
[\mathrm{HX}]_{\mathrm{e} . \mathrm{p} .}=\frac{\sqrt{1+4 K_{\mathrm{BHX}} C_{\mathrm{B}}}-1}{2 K_{\mathrm{BHX}}}
$$

Equation (14) shows that $[\mathrm{HX}]_{\text {e.p. }}$ is affected by the values of $K_{\mathrm{BHX}}$ and $C_{\mathrm{B}}$.

For the case of crystal violet, the relation between the values of complementary color 


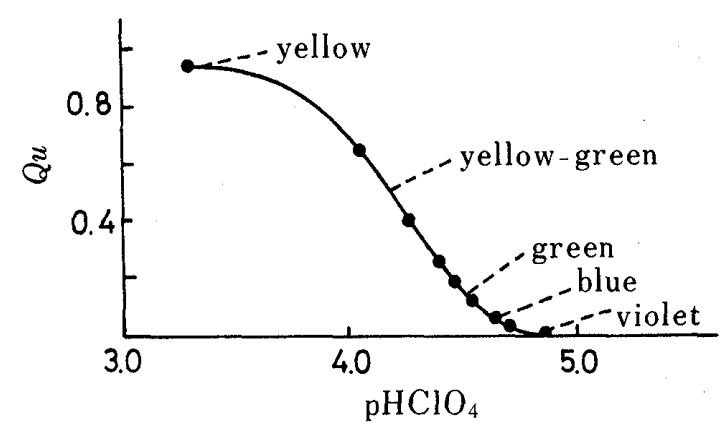

Fig. 3. Relation of $Q u$ to $\mathrm{pHClO}_{4}$ for Crystal Violet

Color transitions of the indicator are marked at the corresponding parts of the curve.

Crystal violet: $5 \times 10^{-6} \mathrm{M}$.

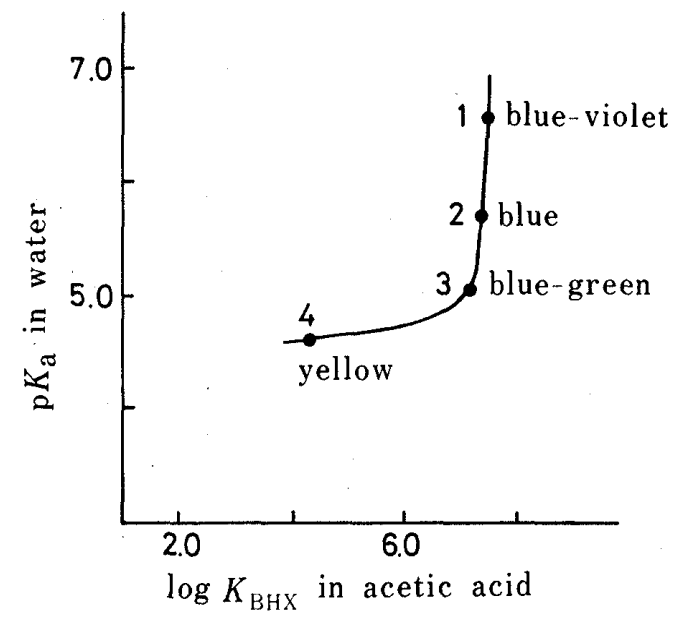

Fig. 4. Relation between $\log K_{\mathrm{BHX}}$ in Acetic Acid and $\mathrm{p} K_{\mathrm{a}}$ in Aqueous Solution for Aniline Derivatives

$C_{\mathrm{B}}, 10^{-2} \mathrm{M} ; \mathrm{C}_{\mathrm{l}}, 5 \times 10^{-6} \mathrm{M}$.

1 , diethylaniline; 2 , dibutylaniline; 3 , dimethylaniline; 4 , crystal violet.

TABLE II. Color Shades of Crystal Violet at the Equivalence Points of Some Aniline Derivatives in Acetic Acid

\begin{tabular}{lccccl}
\hline & $\begin{array}{c}\text { Conc. } \\
(\mathrm{M})\end{array}$ & $\begin{array}{c}\mathrm{p} K_{\mathrm{a}} \\
\text { in aqueous } \\
\text { solution }\end{array}$ & $\begin{array}{c}K_{\mathrm{BHX}} \text { in } \\
\text { acetic acid }\end{array}$ & $\mathrm{pHClO}_{4 \text { e.p. }}$ & $\begin{array}{c}\text { Color shade at } \\
\text { equivalence point }\end{array}$ \\
\hline Diethylaniline & $10^{-2}$ & $6.56^{10)}$ & $2.9 \times 10^{7}$ & 4.732 & Blue-violet \\
Dibutylaniline & $10^{-2}$ & $5.70^{1.1)}$ & $2.7 \times 10^{7}$ & 4.716 & Blue \\
Dimethylaniline & $10^{-2}$ & $5.06^{10}$ & $1.8 \times 10^{7}$ & 4.628 & Blue-green \\
\hline
\end{tabular}

TABLE III. Comparison of Color Shades of Crystal Violet at the Equivalence Points at Different Concentrations

\begin{tabular}{lcccl}
\hline & $\begin{array}{c}\text { Conc. } \\
(\mathrm{M})\end{array}$ & $\begin{array}{c}K_{\mathrm{BHX}} \text { in } \\
\text { acetic acid }\end{array}$ & $\mathrm{pHClO}_{4 \text { e.p. }}$ & $\begin{array}{c}\text { Color shade at } \\
\text { equivalence point }\end{array}$ \\
\hline \multirow{3}{*}{ Barbital Na } & $10^{-2}$ & \multirow{2}{*}{$1.1 \times 10^{7}$} & 4.521 & Green \\
& $10^{-3}$ & & 5.023 & Violet-blue \\
Phenobarbital Na & $10^{-2}$ & $4.2 \times 10^{6}$ & 4.315 & Green-yellow \\
& $10^{-3}$ & 4.817 & Blue-violet \\
\hline
\end{tabular}

$$
C_{\mathrm{I}}: 5 \times 10^{-6} \mathrm{M}
$$

points and $\mathrm{pHClO}_{4}$ is shown in Fig. 3. The color shade of crystal violet at the equivalence point can be decided by utilizing both the calculation result from Eq. (14) and Fig. 3. The results for some aniline derivatives are listed in Table II. When the titrations were stopped at the selected color shade, the error was within $\pm 1 \%$ for $10^{-2} \mathrm{M}$ order sample solutions.

The $\mathrm{p} K_{\mathrm{a}}$ values of various aniline derivatives measured in the aqueous solution are listed in Table II. It appears that $K_{\mathrm{BHX}}$ values in anhydrous acetic acid also decrease with decreasing $\mathrm{p} K_{\mathrm{a}}$ values in aqueous solution. The relation between $\log K_{\mathrm{BHX}}$ and $\mathrm{p} K_{\mathrm{a}}$ is plotted in Fig. 4 and the color shade of crystal violet at the equivalence point is also shown. Thus, without the 
calculation of $K_{\mathrm{BHX}}$, the color shade of the visual end-point in anhydrous acetic acid could be determined from the $\mathrm{p} K_{\mathrm{a}}$ value of the sample in aqueous solution. However, when the $\mathrm{p} K_{\mathrm{a}}$ value reached 5.0, the conditional stability constant of the sample and the titrant decreased sharply because of its weak basicity. Thus, $K_{\mathrm{BHX}}$ must be higher than $K_{\mathrm{IHX}}, 2.7 \times 10^{4}$ for a sample of $\mathrm{p} K_{\mathrm{a}}$ below 5.0 .

The variation of sample concentration also causes a change of color shade at the equivalence point, and the color tends to change from violet to green, and eventually to yellow, at higher concentrations. The color changes at different concentrations of some barbital derivatives are listed in Table III. The titration error increased for a $10^{-3} \mathrm{M}$ order sample solution because the color shade at the equivalence point was close to violet, where color change is poorly perceived by the human eye.

\section{Determination Results by Complementary Color Point Method}

Visual titration is a convenient technique for a simple determination, but some operator errors are inevitable, especially in non-aqueous titration. From Eqs. (6) - (10), we have Eq. (15).

$$
C_{\mathrm{B}}=\left(C_{\mathrm{HX}}-[\mathrm{HX}]-\frac{K_{\mathrm{IHX}}[\mathrm{HX}] C_{\mathrm{I}}}{1+K_{\mathrm{IHX}}[\mathrm{HX}]}\right)\left(\frac{1}{K_{\mathrm{BHX}}[\mathrm{HX}]}+1\right)
$$

The $\mathrm{pHClO}_{4}$ in the vicinity of the equivalence point may be found from Fig. 3 by calculation of the complementary color point, and so $C_{\mathrm{B}}$ is calculated from Eq. (15) without operator error even at a sample concentration of $10^{-3} \mathrm{M}$. The results for barbital sodium and phenobarbital sodium are shown in Table IV.

\section{Determination Results by Indicator Transition Method}

We reported in our previous paper that Eq. (16) holds for the vicinity of the equivalence point where the color transition of the indicator has begun, and that the experimental results agree well with the theoretical curve near the equivalence point.

$$
C_{\mathrm{B}}=\left(\frac{K_{\mathrm{IHX}}}{K_{\mathrm{BHX}}} \frac{\phi}{1-\phi}+1\right)\left\{C_{\mathrm{HX}}-\frac{1}{K_{\mathrm{IHX}}} \frac{1-\phi}{\phi}-(1-\phi) C_{\mathrm{I}}\right\}
$$

TABLE IV. Determination Results by Complementary Color Point Method

\begin{tabular}{lccccc}
\hline \hline & $\begin{array}{c}\text { Taken } \\
(\mathrm{M})\end{array}$ & $Q u$ & $\mathrm{pHClO}_{4}$ & {$\left[\mathrm{HClO}_{4}\right]$} & $C_{\mathrm{B}}$ \\
\hline \multirow{3}{*}{ Barbital Na } & $10^{-2}$ & 0.065 & 4.70 & $1.97 \times 10^{-5}$ & $9.87 \times 10^{-3}$ \\
& $10^{-3}$ & 0.035 & 4.75 & $1.75 \times 10^{-5}$ & $9.85 \times 10^{-4}$ \\
Phenobarbital Na & $10^{-2}$ & 0.046 & 4.73 & $1.88 \times 10^{-5}$ & $9.95 \times 10^{-3}$ \\
& $10^{-3}$ & 0.033 & 4.76 & $1.73 \times 10^{-5}$ & $9.84 \times 10^{-4}$ \\
\hline
\end{tabular}

TABLE V. Determination Results by Indicator Transition Method

\begin{tabular}{lccccc}
\hline \hline & $K_{\mathrm{BHX}}$ & $\begin{array}{c}\text { Taken } \\
(\mathrm{M})\end{array}$ & $(\mathrm{M})$ & $\begin{array}{c}\text { Found } \\
(\text { S.D. })\end{array}$ & $\begin{array}{c}\text { Purity } \\
(\%)\end{array}$ \\
\hline \multirow{2}{*}{ Sodium benzoate } & \multirow{2}{*}{$1.3 \times 10^{6}$} & $10^{-3}$ & $0.986 \times 10^{-3}$ & 0.003 & 98.6 \\
& & $10^{-4}$ & $0.979 \times 10^{-4}$ & 0.003 & 97.9 \\
DL- $\alpha$-Methyl DOPA & \multirow{2}{*}{$7.8 \times 10^{5}$} & $10^{-3}$ & $0.981 \times 10^{-3}$ & 0.004 & 98.1 \\
& & $10^{-4}$ & $0.972 \times 10^{-4}$ & 0.004 & 97.2 \\
Antipyrine & $4.5 \times 10^{4}$ & $10^{-3}$ & $0.952 \times 10^{-3}$ & 0.005 & 95.2 \\
& & $10^{-4}$ & $0.915 \times 10^{-4}$ & 0.007 & 91.5 \\
\hline
\end{tabular}


Here, $\phi$ is the indicator transition and is defined as

$$
\phi=\frac{[\mathrm{I}]}{C_{\mathrm{I}}}
$$

We tried to apply the equation to samples having conditional stability constants of comparatively small values. The sample concentrations were of the order of $10^{-4}-10^{-3} \mathrm{M}$ and Eq. (14) could not be applied.

The results of determination of some weak bases by the use of Eq. (16) are listed in Table V. Sample solutions of $10^{-4} \mathrm{M}$ sodium benzoate, DL- $\alpha$-methyl dihydroxyphenylalanine (DOPA) and antipyrine correspond to $14.0 \mu \mathrm{g} / \mathrm{ml}, 21.0 \mu \mathrm{g} / \mathrm{ml}$ and $19.0 \mu \mathrm{g} / \mathrm{ml}$, respectively. From Table V, it appears that the titration error tends to increase with decreasing value of the conditional stability constant in the acetic acid solvent. The experimental error for antipyrine was particularly large, since $K_{\mathrm{BHX}}$ of antipyrine was close to $K_{\mathrm{IHX}}$ of the indicator, as discussed above.

\section{References}

1) A. Ringbom, "Treatise on Analytical Chemistry," Part II, Vol. 2, ed. by I. M. Koltoff and P. J. Elving, Interscience Encyclopedia, New York, 1979, p. 487.

2) I. M. Koltoff and S. Bruckenstein, J. Am. Chem. Soc., 78, 1 (1956).

3) M. Tanaka and G. Nakagawa, Anal. Chim. Acta, 33, 543 (1965).

4) S. Yoshida, K. Oda and S. Hirose, Chem. Pharm. Bull., 29, 1662 (1981).

5) H. Flaschka, Talanta, 8, 342 (1961).

6) S. Yoshida and S. Hirose, Bunseki Kagaku, 23, 901 (1974).

7) T. Yoshimura, Bunseki, 5, 106 (1979).

8) M. Tanaka and G. Nakagawa, Anal. Chim. Acta, 32, 123 (1965).

9) J. Kucharsky and L. Safarik, "Titration in Non-Aqueous Solvents," Elsevier Pub., New York, 1965, p. 77.

10) N. F. Hall and M. R. Sprinkle, J. Am. Chem. Soc., 54, 3469 (1932).

11) G. Baddeley, J. Chadwick and J. T. Taylor, J. Chem. Soc., 1956, 448. 